Article

\title{
Clustering Coastal Land Use Sequence Patterns along the Sea-Land Direction: A Case Study in the Coastal Zone of Bohai Bay and the Yellow River Delta, China
}

\author{
Zhi Ding ${ }^{1,2}$, Fenzhen Su ${ }^{2, *}$, Junjue Zhang ${ }^{2}$, Yu Zhang ${ }^{2}$, Shuchang Luo ${ }^{1}$ and Xuguang Tang ${ }^{1}$ \\ 1 Chongqing Engineering Research Center for Remote Sensing Big Data Application, School of Geographical \\ Sciences, Southwest University, Chongqing 400715, China \\ 2 State Key Laboratory of Resources and Environmental Information System, Institute of Geographic Sciences \\ and Natural Resources Research, Chinese Academy of Sciences, Beijing 100101, China \\ * Correspondence: sufz@lreis.ac.cn; Tel.: +86-10-64888956
}

Received: 22 July 2019; Accepted: 23 August 2019; Published: 28 August 2019

\begin{abstract}
Specific knowledge about the characteristics of coastal land use along the sea-land direction helps to better understand the spatial heterogeneity of coastal land use, which could offer scientific support for rational land management and the sustainable development of the coastal zone. However, the traditional methods including buffering or the regional method are hard to extract detailed spatial structure and location correlations of coastal land use along the sea-land direction. Therefore, we developed a model, called sequence-based clustering of coastal land use pattern (SCCLUP), to mine the coastal land use sequence patterns (CLUSPs) along the sea-land direction. As a case study in the major coastal zone of Bohai Bay and the Yellow River Delta from 1990 to 2010, we found that: (1) The land use showed a sequential distribution along the sea-land direction. And the land use closed to shoreline and inland boundary had relative stable sequential location along the sea-land direction. However, the middle land uses had dynamic sequential locations that led to multiple CLUSPs; (2) due to the increasing percent of construction land, the artificial level of CLUSPs was continuously increasing and new CLUSPs tended to distribute around port areas. Different CLUSPs with similar land use sequential relationships tended to have similar land use structure along the sea-land direction; (3) the land uses sequential location along the sea-land direction revealed the actual distance of land use to the shoreline and had a tight correlation with environmental factors (salinity, water, and landform). The land use with large increasing and wide adaptivity (like construction land) had a large impact on the changes of CLUSPs in the study area. Therefore, strong control should be provided for the excessive expansion of land use like construction land to limit the over changes in land use pattern along the sea-land direction. Additionally, the spatial heterogeneity of land use along the sea-land direction should be considered to a better understanding of anthropic impacts on the coastal zone.
\end{abstract}

Keywords: PAM; sea-land direction; land use change; sequence pattern; temporal and spatial heterogeneity

\section{Introduction}

The coastal zone, which plays a key role in the Earth system, is a unique place surrounded by the ocean, atmosphere, and earth [1-3]. Being influenced by terrestrial factors and marine factors and land-ocean interactions (LOIs), the coastal zone exhibits regular spatial characteristics along the sea-land direction, including the physiographic gradient, physiochemical gradient, and biogenic gradient. In geomorphologic and hydrological terms, the coastal zone is divided into different parts from sea to land $[3,4]$. Simultaneously, salinity and soil moisture content decrease with increasing 
distance from the sea [5]. Additionally, affected by physiographic factors, biogenic factors, and physiochemical factors, coastal land use (landscape) also shows a regular spatial distribution pattern with increasing distance from the sea [6-8]. For example, water bodies and residential areas appeared the most notable seaward [8]. However, the land use adaption to an environment gradient leads to the wide distribution of some land uses along the sea-land direction and add more uncertainty of the land use gradient along the sea-land direction. Meanwhile, due to climate difference $[9,10]$, landform difference, and different anthropic disturbance $[8,11]$, the land use may be changed with the different coastal regions. Additionally, the possible land use gradient along the sea-land direction may also have some variations. In fact, climate change and anthropic disturbances have large impacts on the coastal landscape. In terms of sea level rise due to climate change, low-lying coastal areas, particularly those areas closest to the coast, are at risk of coastal erosion and may even disappear in the future due to the sea level rise $[1,12,13]$. Due to high anthropic disturbance, large areas of coastal wetland and farmland have been drained and converted to other anthropic land use [14,15]. In the end, the land uses spatial pattern along the sea-land direction may be changed [16] and the uncertainty of the land use gradient becomes further worse with a regional difference and dynamic factors (climate change and anthropic disturbance). How to distinguish the regular land use spatial pattern along the sea-land direction is the key precondition for research on the coastal land use gradient and help to understand the impacts from anthropic disturbance on the land spatial pattern along the sea-land direction. Knowledge about the impacts from anthropic disturbance could offer scientific support for rational land management and the sustainable development of the coastal zone.

The field study is one of the most reliable methods to investigate the spatial distribution of coastal land use along the sea-land direction. According to the samples obtained from sequential locations along the sea-land direction, it was found that salt vegetation often shows predictable patterns of zonation along with salinity and soil moisture content gradient due to the interaction of land and sea [17-19]. Meanwhile, the salinity gradient may change with the land-use type from vegetable fields to tidal flats, corresponding to long-term cultivated soil to newly deposited natural sediments [6]. In this sense, the coastal land use spatial pattern may indicate the coastal environment gradient factors like salinity and soil moisture content gradient along the sea-land direction [20]. However, due largely to the time and human costs, field study is difficult to apply to research on land use in large areas. Remote sensing data with wide-range, high spatial resolution, and long-time series realize land use study on the large areas and long periods. Additionally, remote sensing-based land use pattern research has become popular and has been widely applied in the coastal areas.

The buffer method, dividing the study area into predefined subzones, is one of the most popular ways to extract the land use spatial pattern along the sea-land direction [17-22]. Based on the buffer of the coastal zone along the sea to land, Hou et al. (2011) found remarkable sea-land gradient characteristics of land use following the changes of distance to coastline [8]; in the coastal zone of Jiangsu Province, China, Xu et al. (2012) also found a low-high-low pattern of land use diversity (indicated by counts of land-use types) along the sea to land. However, land use intensity (calculated by the Land Use Intensity Comprehensive Index (LUICI), which reflects the influence degree of human activities) showed a high-middle-low pattern along the sea to land [21]. For example, in the coastal zone of China, Di et al. (2015) found that there was a significant sea-land gradient for land use intensity, which was low in the island and near-shore areas, but high in the regions that were 4-30 km away from the coastline [22]. From the above, we can know that land use structure, land use diversity, and land use intensity of the coastal zone have regular spatial distribution along the sea-land direction. However, the spatial relationships between different land use, including spatial location relationships and spatial distance relationships along the sea to land, were rarely discussed. Moreover, the buffer method has some human subjectivities with the definition of the subzone, and it is also difficult to distinguish the spatial relationship between land uses inside of one subzone. Therefore, a new method to distinguish the land use spatial pattern contained the spatial relationships along the sea-land direction is needed. 
The Digital Shoreline Analysis System (DSAS) is an effective tool to analyze the dynamics of the shoreline along the sea-land direction $[23,24]$. However, DSAS mainly focuses on the dynamics of land use in the narrow region approaching the shoreline, such as the intertidal zone or tidal zone $[25,26]$. The supratidal zone or area far from the shoreline in the coastal zone are usually ignored due to the short transect line and the spatial relationships among different land-use types on the transect line have not been discussed. Therefore, we extended the length of the transect line to the boundary of the land part of the coastal zone to explore the characteristics of land use along the sea-land direction for the whole coastal zone. In this way, the transect line is regarded as one small coastal zone and the land use pattern along the sea-land direction in smaller scale could be explored easily by the line features. In the end, based on the powerful ability of the clustering to mine effective information from complex data, we developed a model called sequence-based clustering of coastal land use pattern (SCCLUP) to mine the major coastal land use sequence patterns (CLUSPs) that indicated the sequential location relationship between land-use types along the sea-land direction. We also selected the coastal zone of Bohai Bay and the Yellow River Delta (YRD), China as a case study to explore the spatial distribution of coastal land use along the sea-land direction. The case study area contains one famous bay (Bohai Bay) and one of the largest estuaries (YRD), which has come to be considered as China's "third engine" [27]. Meanwhile, this region has experienced dramatic land use change due to anthropic disturbance, like sea reclamation [11]. Large areas of marshland and the tidal flat have been converted to residential land, ports, and shrimp ponds along the coast [28]. Cultivated land has also suffered a noteworthy loss. In the local area of the YRD, the vegetation distribution patterns in the salt marshes have changed from a zonal pattern to a mosaic pattern due to sea reclamation [15]. Therefore, this case study area is a typical region to explore the differences in land use along the sea-land direction and the changes caused by human activities.

The major objectives of this study were to (1) present a model to mine the major CLUSPs that indicated the spatial location relationship between land-use types along the sea-land direction; (2) explore the temporal and spatial pattern of land use along the sea-land direction; and (3) analyze the uncertainty of land use spatial pattern along the sea-land direction.

The remainder of the paper is organized as follows: Section 2 introduces the framework of methodology and the model of SCCLUP. Section 3 introduces the background of the study area and the preprocessing of land use data used in the study. Section 4 presents the result of CLUSP along the sea-land direction from 1990 to 2010 and the spatial and temporal changes of them. Section 5 discusses the relationships between CLUSP and environmental factors (distance to shoreline, salinity, water, and landform). Additionally, the uncertainty of land use spatial pattern along the sea-land direction is discussed accordingly. Section 6 concludes the paper.

\section{Methodology}

The methodology consists of preprocessing of data and the model of SCCLUP. In the preprocessing of data, the coastal zone is sampled into regular transect lines perpendicular to the shoreline, and the land-use features on the transect lines are numbered sequentially to indicate the land use spatial location along the sea-land direction. SCCLUP is a data mining model to mine the typical land use sequential patterns along the sea-land direction. The overall framework of the methodology is shown in Figure 1. 


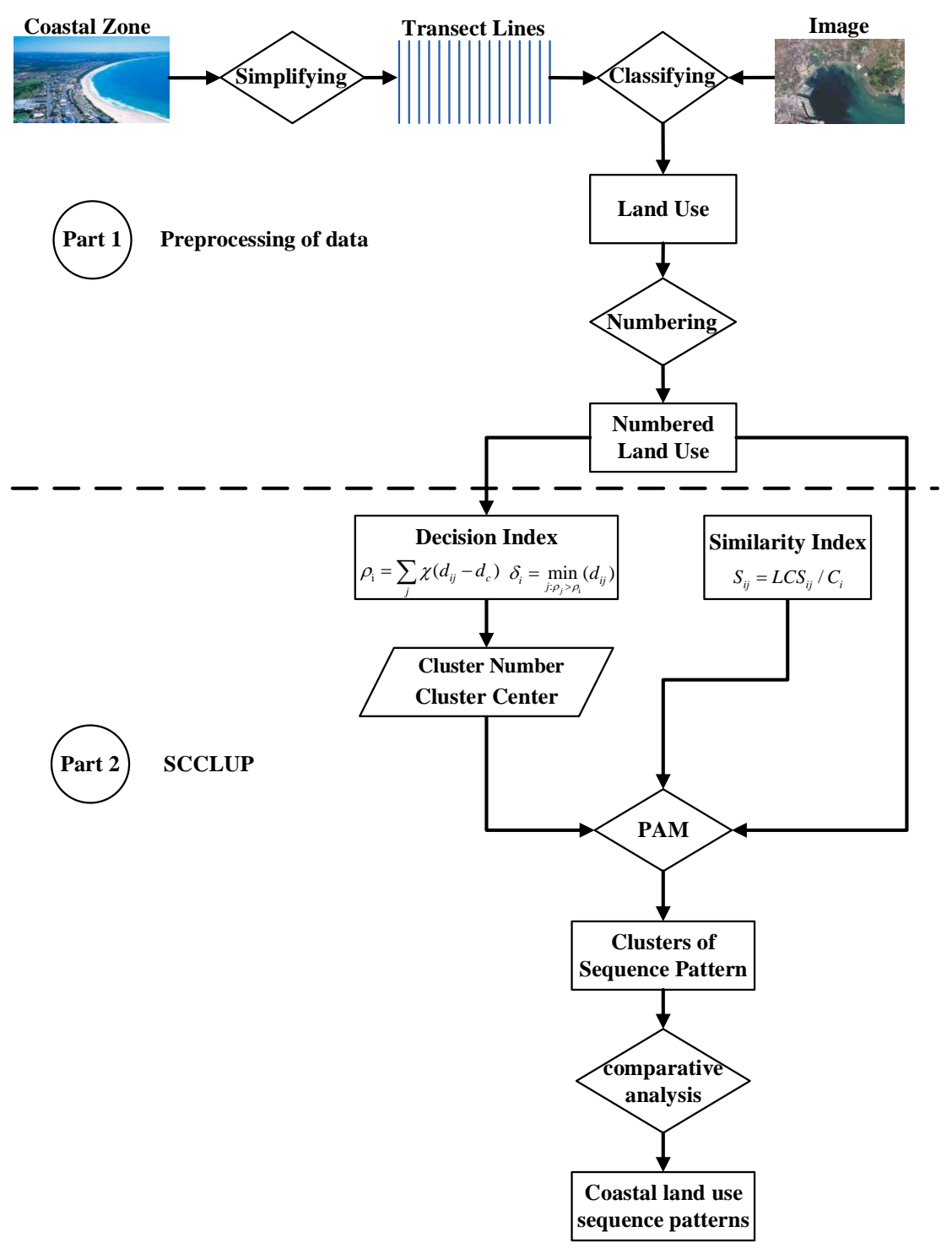

Figure 1. The overall framework of the methodology.

\subsection{Preprocessing of Data}

The transect lines of the coastal zone are defined by the length of the line and the distance between lines. In this study, the length of the transect line is defined as the width of the coastal zone along the sea-land direction. The distance between adjacent lines indicates the sample scale of the coastal zone along the horizontal direction. The smaller value of the distance, the narrower coastal zone regarded by the transect line. In this study, the distance is defined as the value of spatial resolution of the original remote sensing image of the land use data. Another method is defined as the minimum value of the size of the minimum feature in the study area. In this way, all land-use features would be covered by the transect lines. Based on the construction of coastal transect lines in DSAS, we developed software to construct the transect lines in this study.

The land use data of the coastal transect line (Figure 2) is extracted by manual interpretation based on the predefined land use classification system. In order to distinguish the sequential relationship between land-use types, land-use features on the transect lines were numbered sequentially along the sea-land direction. However, some land-use types (like construction land) on one line may occur more than once, which may lead to uncertain sequential relationships between different land-use types (e.g., construction land and forestland). Therefore, we number the land-use types based on the value of the defined average number in the transect. The average number of one land-use type was the average 
value of the total numbers of this land-use type. If different land-use types with the same average number were equal, the sequential relations among these land-use types were decided by the start number of the largest land-use segments in one line. Finally, the numbers were sorted by the average number for each land-use type, and the sorted number is defined as the final sequence number. The process of numbering the land-use types in one line is illustrated in Figure 3.

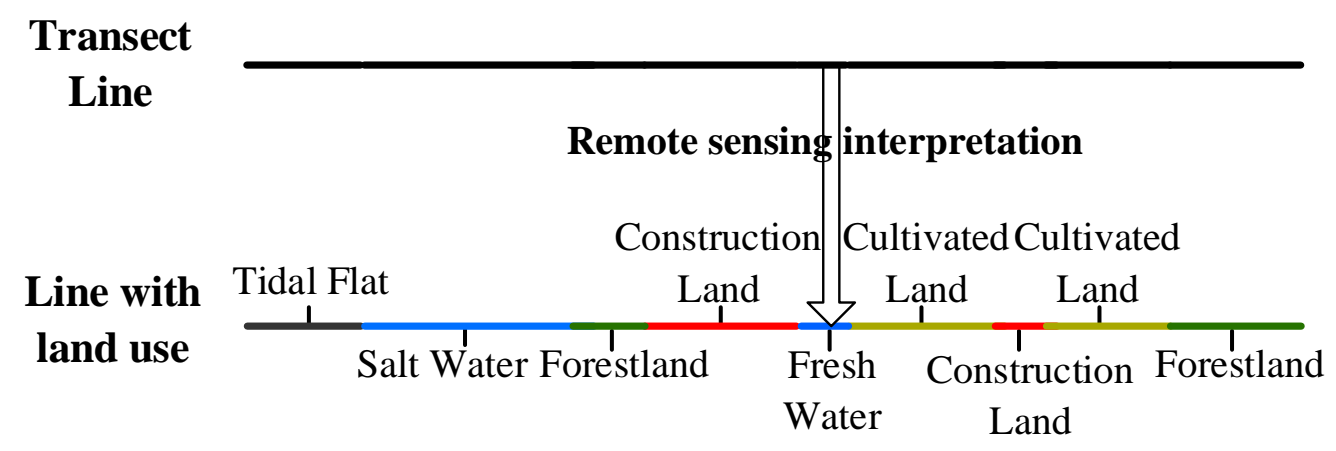

Figure 2. The coastal transect line land use.

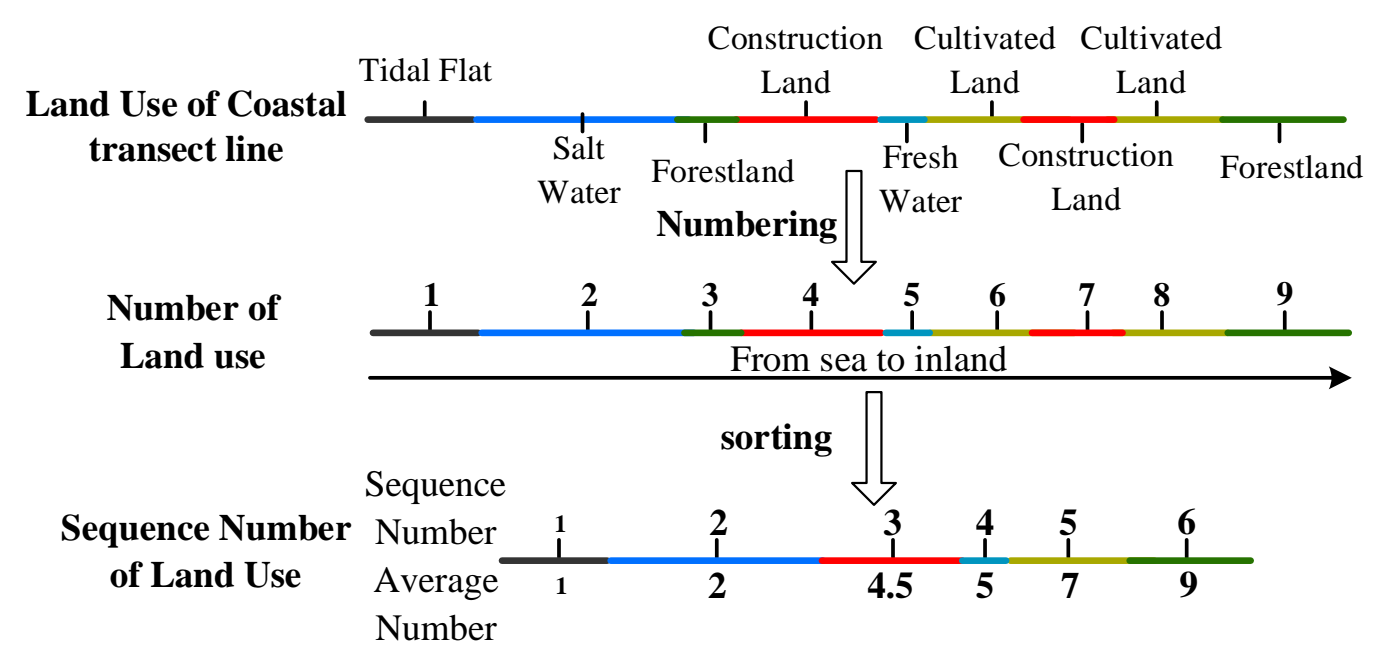

Figure 3. The process of numbering the land-use types in one line.

\subsection{The SCCLUP Model}

SCCLUP consists of three parts including the clustering method, defining the cluster centers and numbers, and sequence-based similarity index for coastal land use.

\subsubsection{Clustering Method-Partitioning around Medoids (PAM)}

PAM is a well-known clustering algorithm for being simple and fast, which aims to find the $\mathrm{k}$ medoids and assigns every object to the nearest medoid that is the object with the shortest distance to the other objects in the cluster $[29,30]$. Compared with K-means, PAM is more robust, with few impacts from noisy data [31]. Therefore, we chose PAM as the clustering algorithm.

\subsubsection{Defining the Cluster Centers and Numbers}

However, like most clustering algorithms, PAM requires a predefined cluster number of $\mathrm{k}$ and cluster centers (medoids) those are difficult to choose. Researchers have presented various clustering strategies [32-35], but no consensus has been reached even on the definition of a cluster. One simple and effective method was proposed to recognize the clusters (cluster centers and numbers) [36-38]. The key idea of the method is that cluster centers are surrounded by neighbors with lower local density and that they are at a relatively large distance from any points with a higher local density [39]. 
This method is widely used in many clustering studies [40-43]. Therefore, we used the idea of the above method to choose the proper cluster centers and numbers. The clusters are mainly determined by two quantities: local density $\rho_{i}$ (Equation (1)) and its distance $\delta_{i}$ (Equation (2)) from points of higher density. Both these quantities depend only on the distances $d_{i j}$ between data points, which are assumed to satisfy the triangular inequality. The local density $\rho_{i}$ of data point $\delta_{i}$ is defined as:

$$
\rho_{i}=\sum_{j} \chi\left(d_{i j}-d_{c}\right)
$$

where $\rho_{i}$ is the local density of point $i ; d_{i j}$ is the distance between point $i$ and point $j$, and $d_{c}$ is a predefined cutoff distance. $\chi(x)=1$ if $x<0$ and $\chi(x)=0$ otherwise:

$$
\delta_{i}=\min _{j: \rho_{j}>\rho_{i}}\left(d_{i j}\right)
$$

where $\delta_{i}$ is the minimum distance between point $i$ and any other point with a higher density. For the point with the highest density, the $\delta_{i}$ is the $\max _{j}\left(d_{i j}\right)$.

Generally, the value of $\delta_{i}$ much larger than the typical nearest neighbor distance for points with local or global maxima in the density. The cluster centers are defined as points with anomalously large $\delta_{i}$. The anomalous points (cluster centers) are easily observed by the scatter points graph of $\delta_{i}$ and $\rho_{i}$. Additionally, a hint for choosing the number of centers is provided by the plot of $\gamma_{i}$ (Equation (3)) sorted in decreasing order and the $\gamma_{i}$ is defined as:

$$
\gamma_{i}=\rho_{i} * \delta_{i}
$$

However, the proper candidates of cluster centers may have multiple choices. Therefore, an alternative method for choosing the optimal candidates of $\mathrm{k}$ is needed. The most widely used approaches for cluster validation are based on internal cluster validity indices [44,45]. The Davies-Bouldin (DB) [46] Index (Equation (4)) is probably one of the most widely used indices [44], and was chosen as a validation index in this study. DB estimates the cohesion based on the distance from the points in a cluster to its centroid and the separation based on the distance between the centroids [47]:

$$
D B(k)=\frac{1}{k} \sum_{i=0}^{k} \max _{j=1 \sim k, j \neq i}\left(\frac{w_{i}+w_{j}}{c_{i j}}\right)
$$

where $\mathrm{DB}(k)$ is the value of $\mathrm{DB}$ for cluster number k. $w_{i}$ or $w_{j}$ is the average distance of sample points to the center of cluster center $i\left(c_{i}\right)$ or cluster $j\left(c_{j}\right) . c_{i j}$ is the distance between cluster $c_{i}$ and $c_{j}$. The value of $\mathrm{DB}(k)$ is smaller, the clustering result of $\mathrm{k}$ will be better.

\subsubsection{Similarity Index of Coastal Land Use Sequence Patterns}

To calculate the similarity of coastal land use sequence patterns between coastal sampling lines, we proposed an index called the Sequence Similarity Index (SSI) (Equation (5)) based on the longest common subsequence (LCS) [48,49]:

$$
\mathrm{S}_{i j}=\frac{L C S_{i j}}{C_{i}}
$$

where $S_{i j}$ is the clustering distance from line $i$ to line $j$. In this study, we chose $1 / S_{i j}$ as the clustering index; $L C S_{i j}$ is the longest common subsequence between line $i$ and line $j$; and $C_{i}$ is the number of land-use types in line $i$. 


\section{Study Area and Data}

\subsection{Study Area}

The study area $\left(37^{\circ} 28^{\prime}\right.$ to $39^{\circ} 29^{\prime} \mathrm{N}, 117^{\circ} 15^{\prime}$ to $\left.119^{\circ} 17^{\prime} \mathrm{E}\right)$ (Figure 4$)$, located in the west of Bohai Sea in Northern China, is a muddy coastal plain including Bohai Bay and the Yellow River Delta. The length of the coastline is approximately $1700 \mathrm{~km}$. The elevation is between 0 and $15 \mathrm{~m}$. Mean annual precipitation varies from $520 \mathrm{~mm}$ to $660 \mathrm{~mm}$, and the mean annual temperature ranges from $11^{\circ} \mathrm{C}$ to $13{ }^{\circ} \mathrm{C}$. Many rivers and streams run across the plain, including the Luanhe River, Yongding River, Haihe River, Ziya River, and Yellow River. The dominant soil types are alluvial soil, saline soils, bog soil, and cinnamon soil. The typical vegetation is halophytic plant communities predominated by herb and shrub species [50,51]. The area is one of the most important economic regions in China with large ports, such as Tangshan Port, Tianjin Port, and Huanghua Port.
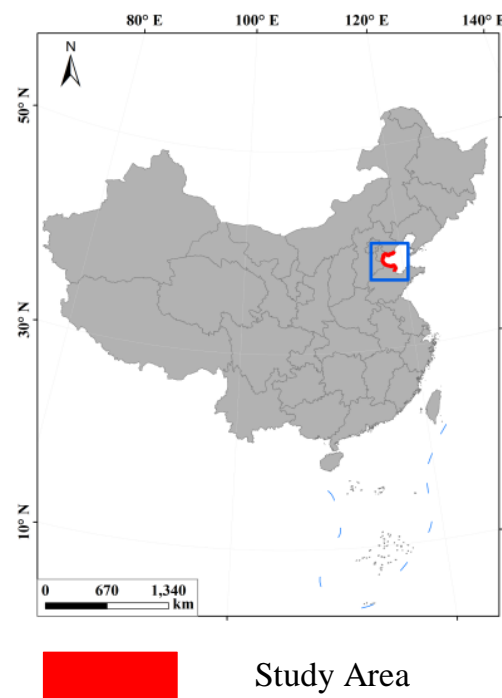

- $\cdots \quad$ Boundary Province

- - Boundary County

River

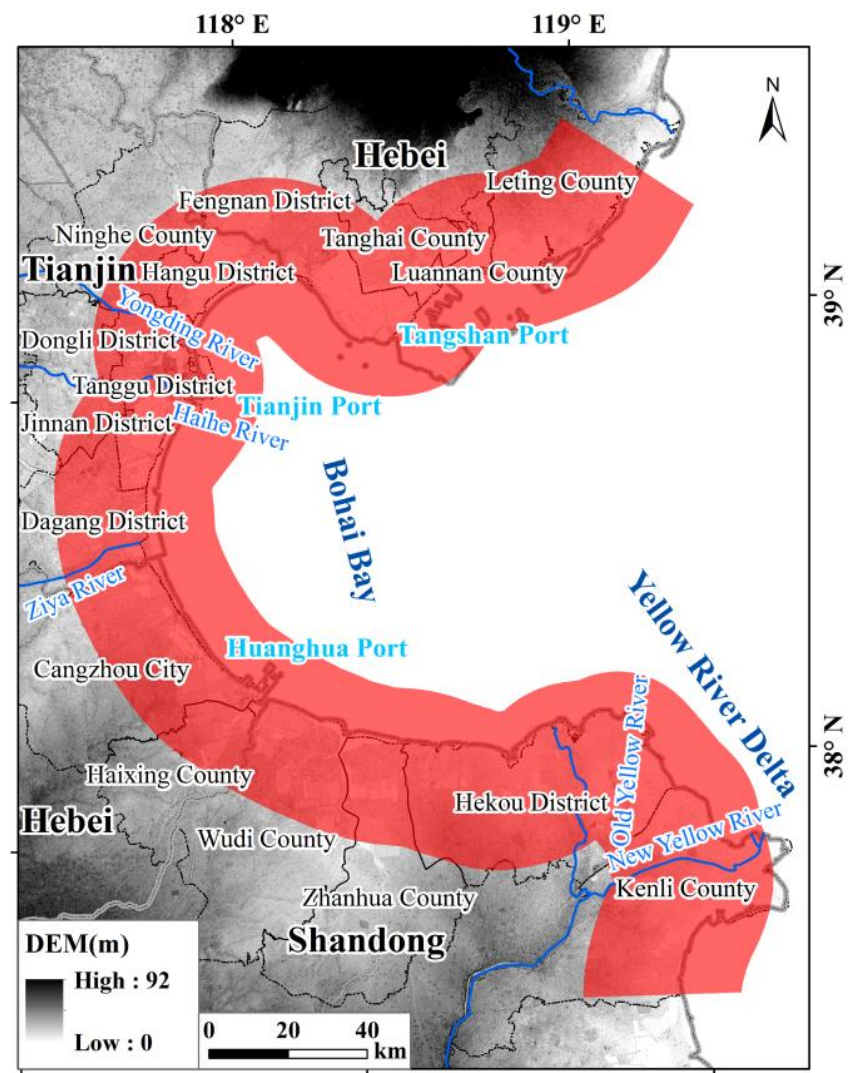

Figure 4. Study area.

\subsection{Data}

The research period was from 1990 to 2010, when the economy developed rapidly in our study area, and the time interval was set to a decade. The land-use data were interpreted from US Landsat TM satellite data with a spatial resolution of $30 \mathrm{~m} \times 30 \mathrm{~m}$. The types and sources of image data used are shown in Table 1. Most of the images were cloud-free. According to the existing coastal land use classification systems [8,22,52] and land use characteristics of the study area [11], we defined our land use classification system as shown in Table 2. In order to ensure the accuracy of the land use data, we used both the machine and manual interpretation to extract the land use data in the study area. Firstly, according to the samples, we used the minimum distance classification to extract the preliminary classification result. The preliminary classification results extracted from the minimum distance classification method were roughly and had some image classification errors (e.g., omission error and commission error). Then, in order to eliminate these classification errors, we corrected them 
through visual interpretation based on the fine spatial resolution image data (Google Imagery) and individual experience. In the end, we used the confusion matrix to check the land use accuracy. Four hundred polygon samples (50 samples for each land-use type) were selected to test the accuracy. The true values of the 400 test samples were determined according to the historical high-resolution images from Google Earth and archived files. The overall accuracy of the land-use data for 1990, 2000, and 2010 was $85.1 \%, 87.7 \%$, and $89.2 \%$, respectively. Tidal flat, salt water, fresh water, construction land, forest land, and cultivated land had a higher accuracy, with 92.1\%, 91.5\%, 91.2\%, 90.1\%, 89.8\%, and $88.7 \%$, respectively. Unused land and grassland had relatively lower accuracies, with $86.8 \%$ and $85.2 \%$, respectively. Compared with the results from the land-use database of the Resources and Environment Scientific Data Center, Chinese Academy of Sciences [53,54], our land use result had higher accuracy.

Table 1. Image data.

\begin{tabular}{ll}
\hline \multicolumn{1}{c}{ Year (Sensor Type) } & \multicolumn{1}{c}{ Path/Row (Date) } \\
\hline \multirow{2}{*}{1990 (TM5) } & $121 / 33(1990.05 .15), 121 / 34(1990.06 .16), 122 / 32$ \\
& $(1990.10 .29), 122 / 33(1990.09 .11), 122 / 34(1990.10 .29)$ \\
2000 (TM5) & $121 / 33(2000.06 .11), 121 / 34(2000.10 .17), 122 / 32$ \\
& $(2000.06 .18), 122 / 33(2000.08 .21), 122 / 34(2000.08 .21)$ \\
2010 (TM5) & $121 / 33(2010.09 .11), 121 / 34(2010.09 .11), 122 / 32$ \\
& $(2010.03 .10), 122 / 33(2010.04 .27), 122 / 34(2010.04 .27)$ \\
\hline
\end{tabular}

Table 2. The land use classification system based on $[8,22,52]$.

\begin{tabular}{cl}
\hline Type (Abbreviation) & \multicolumn{1}{c}{ Explanation } \\
\hline Cultivated Land (CL) & Refers to the land used available to plant crops including paddy field and dryland \\
$\begin{array}{c}\text { Construction Land (CoL) } \\
\text { Salt Water (SW) }\end{array}$ & $\begin{array}{l}\text { Refers to the urban and rural residential areas, transportation land and oil field. } \\
\text { Refers to the shrimp pond and salt pans }\end{array}$ \\
Fresh Water (FW) & $\begin{array}{l}\text { Refers to freshwater areas and water facilities including river, lake and reservoir } \\
\text { and ponds }\end{array}$ \\
Forest Land (FL) & $\begin{array}{l}\text { Refers to the land that is growing trees, shrubs and mangrove forests } \\
\text { Refers to the land that mainly grows herbaceous plant with vegetation covering } \\
\text { Trassland (GL) }\end{array}$ \\
midal Flat (TF) & Refers to the tidal zone between high tide and low tide along the coast \\
Unused Land (UL) & Refers to the bare land that has not been used or is hard to be used. \\
\hline
\end{tabular}

The vector coastal transect lines (Figure 5A) were constructed by the designed software based on the coastline in 2010. The distance between two adjacent coastal simplified lines was $200 \mathrm{~m}$. The distance was defined from the size of the smallest land-use feature in the study area. The line was $40 \mathrm{~km}$ long and separated into two parts equally by the coastline. In the end, we overlaid the vector coastal simplified lines and the polygon land-use data to generate the land-use data of the coastal simplified lines (Figure 5B-D). 

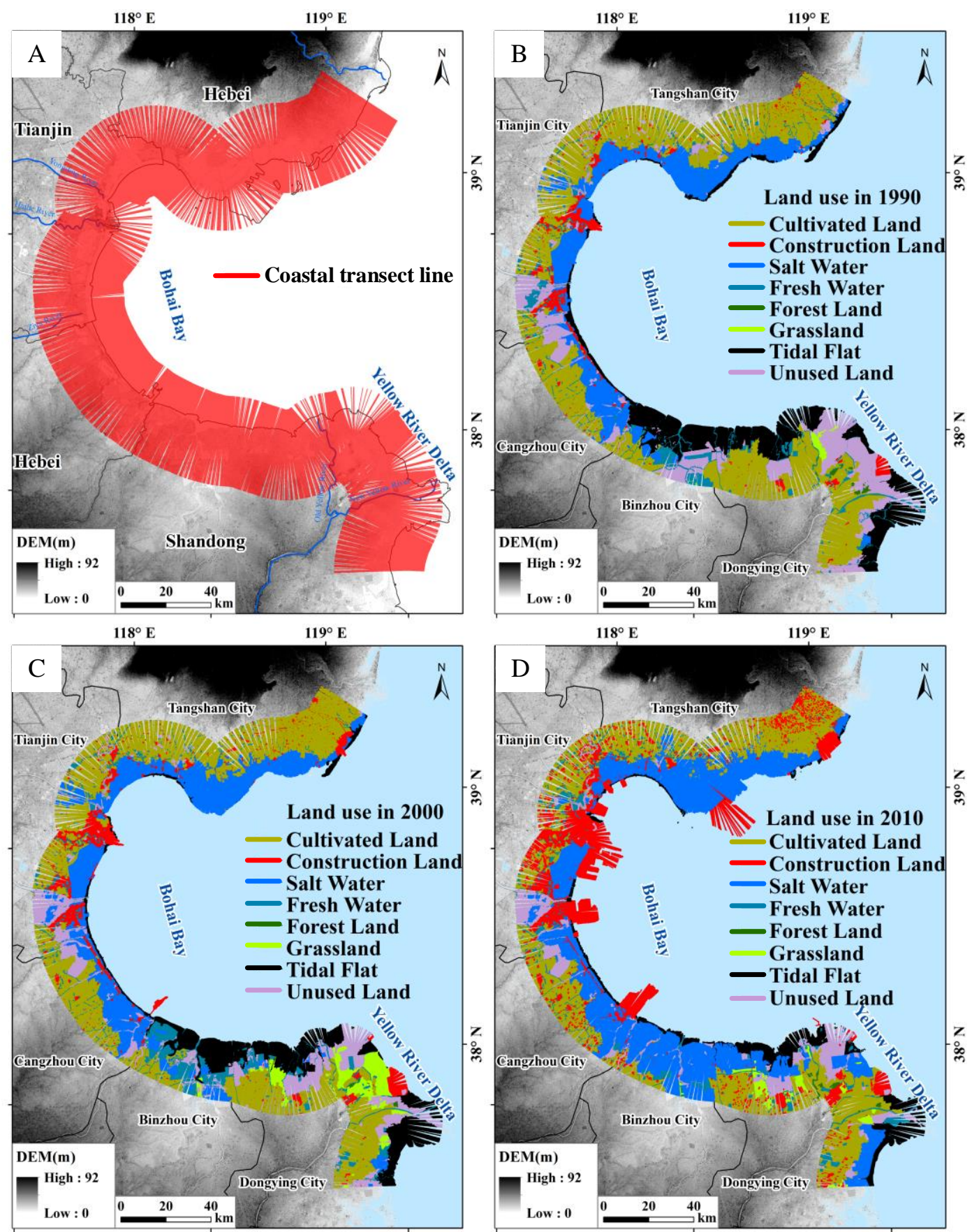

Figure 5. Coastal transect lines (A) and land use data from 1990 to 2010 (B-D).

\section{Results}

With the SCCLUP model, we have mined two CLUSPs, three CLUSPs, and four CLUSPs for 1990, 2000, and 2010, respectively. According to the CLUSPs for 1990, 2000, and 2010, we analyzed the land-use changes along the sea-land direction to demonstrate the spatial location, sequential relationships of the land use along the sea-land direction. Further analysis of temporal and spatial changes of the land use spatial location and sequential relationships are also done.

\subsection{Spatial Location and Relationship among the Land Uses along the Sea-Land Direction from 1990 to 2010}

As a whole, the land uses to show a sequential distribution along the sea-land direction (Figure 6). From 1990 to 2010, tidal flat and unused land have a stable sequential location and mainly distribute 
around places close to the shoreline along the sea-land direction. Forest land also has a stable sequential location and mainly distribute around the farthest places from the shoreline. Unused land and cultivated land have relative stable sequential locations. However, the unused land is only behind salt water and cultivated land and is only in front of forest land along the sea-land direction. The sequential locations of construction land, fresh water, and grassland are changed with the range from the behind of unused land to the front of cultivated land. The dynamic sequential location of the three land-use types leads to the major difference of land use sequential pattern along the sea-land direction in the period of 1990-2010.

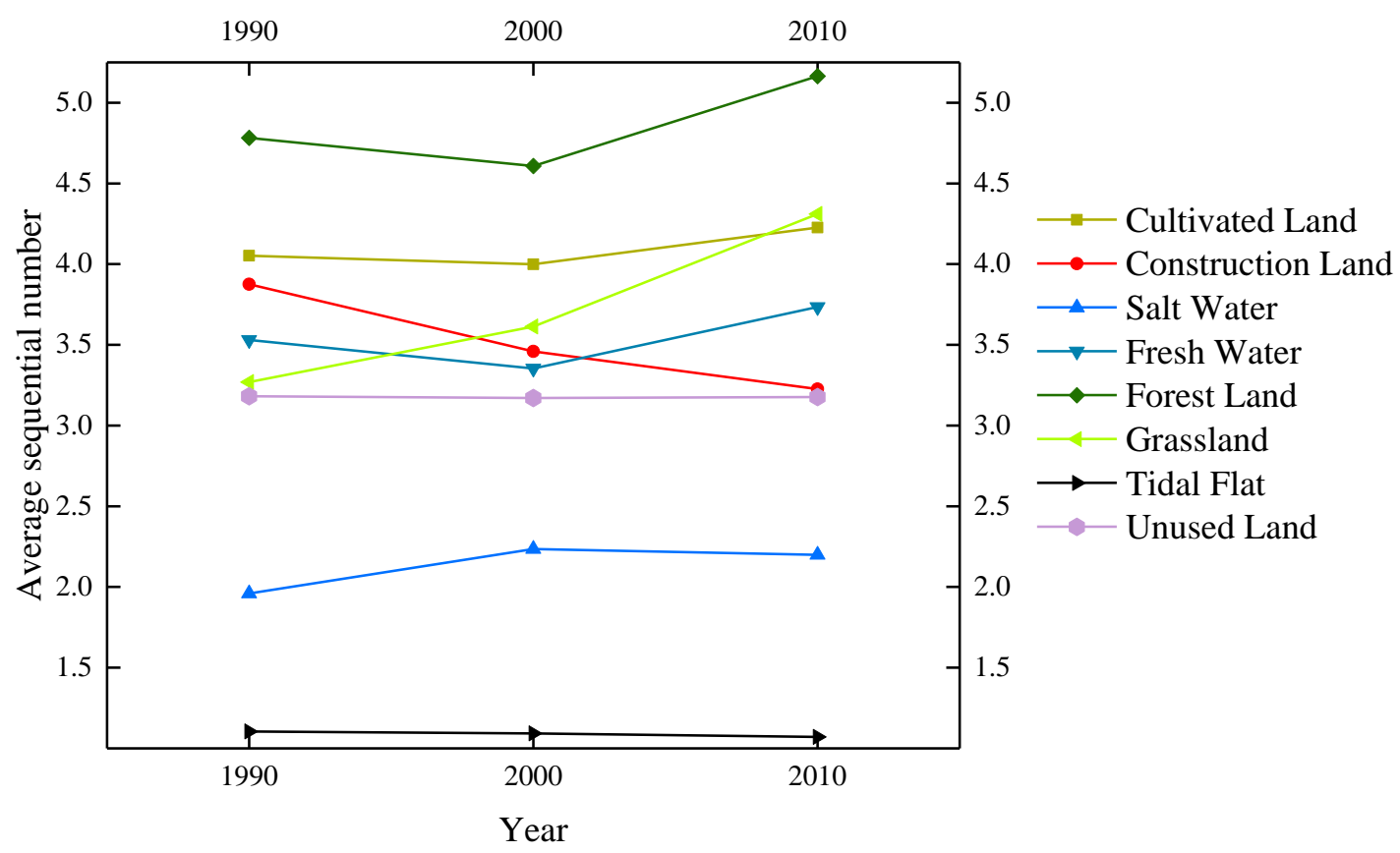

Figure 6. The annual average sequential number of land use along the sea-land direction in the period of 1990-2010.

As Table 3 and Figure 7 showing, although the land uses in CLUSPs from 1990 to 2010 have a trend of sequential distribution along the sea-land direction, the uncertainty of sequential location of land use along the sea-land direction is continuously increasing with dynamic sequential locations of land use in CLUSPs for one year and among years from 1990 to 2010. The sequential locations of tidal flat and salt water are also still stable. The uncertainty of the sequential location of the other land-use types including unused land, fresh water, grassland, construction land, cultivated land, and forest land is indicated by the dynamic sequential relationships between adjacent land uses along the sea-land direction. For example, the unused land, cultivated land, and forest land with the relative stable sequential location in the whole have alternations of sequential locations in CLUSPs along the sea-land direction from 2000 to 2010. For CLUSP 3 in 2000, the cultivated land is behind of forest land. In 2010, the unused land is behind of forest land and adjacent to the cultivated land with the farthest distance from the shoreline. However, the range of the sequential number of the three land-use types mentioned above is relative stable. Cultivated land and forest land had a small sequential location range from 5 to 8 . Both had a higher sequential number and tended to distribute around places far from the shoreline. The sequential numbers of unused land were around 3-7 and 8/9 of them concentrated around the $3-5$ range. 
Table 3. CLUSPs from 1990 to 2010.

\begin{tabular}{cccccccccc}
\hline Year & Cluster ID & \multicolumn{6}{c}{ Sequential Pattern of Land Use along the Sea-Land Direction } \\
\hline \multirow{2}{*}{1990} & 1 & TF & SW & UL & FW & GL & CoL & CL & FL \\
& 2 & TF & SW & GL & CoL & UL & CL & FW & FL \\
\hline \multirow{3}{*}{2000} & 1 & TF & SW & UL & FW & GL & CoL & CL & FL \\
& 2 & TF & SW & GL & UL & CL & FW & FL & CoL \\
& 3 & TF & SW & CoL & UL & GL & FL & FW & CL \\
\hline \multirow{3}{*}{2010} & 1 & TF & SW & UL & CoL & FW & GL & CL & FL \\
& 2 & TF & SW & UL & FW & FL & GL & CL & CoL \\
& 3 & TF & SW & GL & FW & CoL & FL & UL & CL \\
& 4 & TF & CoL & SW & FW & UL & CL & FL & GL \\
\hline
\end{tabular}

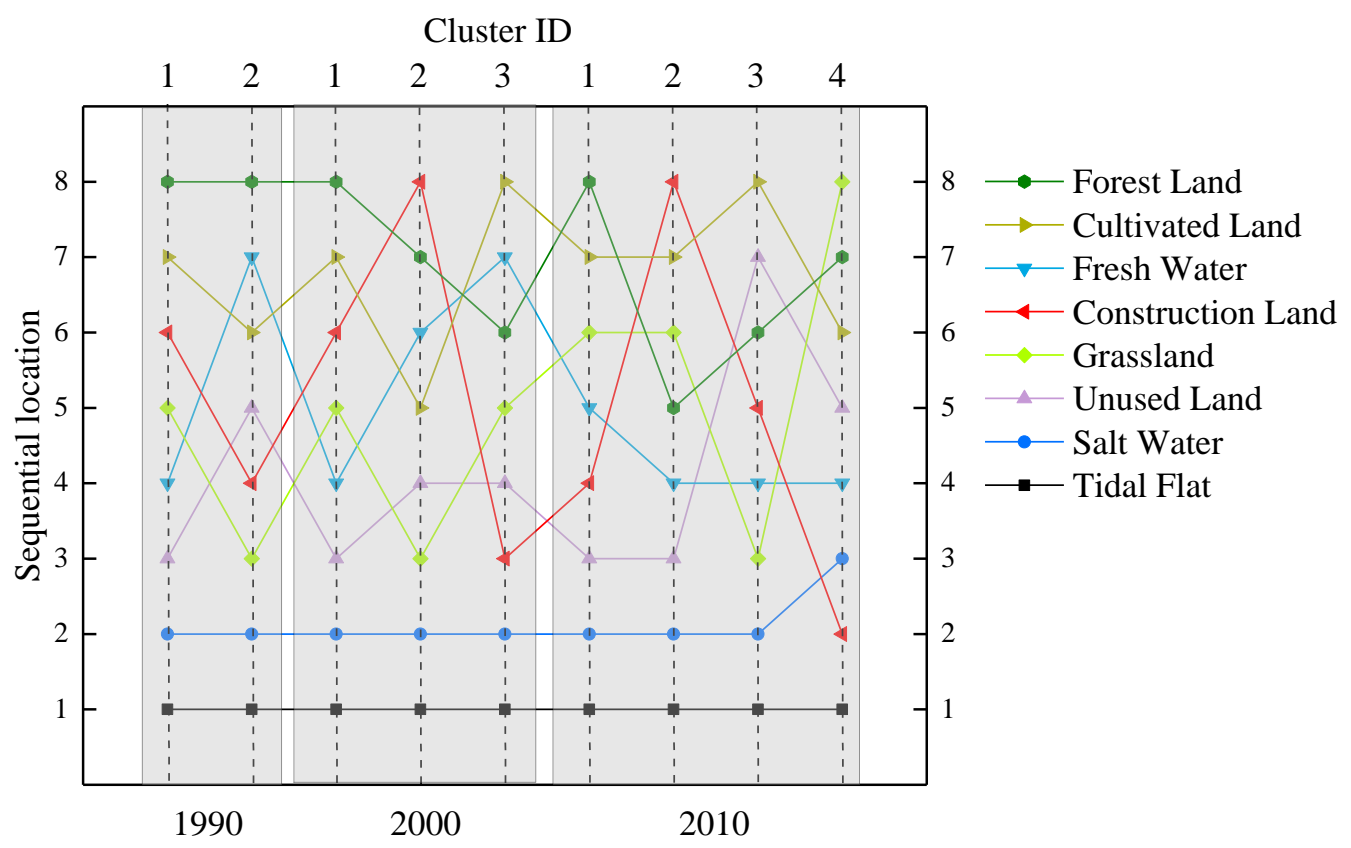

Figure 7. The sequential number of each land-use type in the CLUSPs from 1990 to 2010.

According to the sequential distribution of land use along the sea-land direction, the sequential relationships between adjacent land uses among the CLUSPs are also relatively stable. With the stable sequential location along the sea-land direction, the sequential location behind that of tidal flat along the sea-land gradient was usually that of Salt Water. Following salt water were mainly unused land and grassland with rates of $44.44 \%(4 / 9)$ and $33.33 \%(3 / 9)$, respectively. For unused land, salt water was often in front of it with the highest rate of $44.44 \%$ (4/9) and cultivated land was often behind it with the highest rate of $44.44 \%$ (4/9). The land-use types before fresh water and construction Land tended to be diverse, especially since construction land had seven land-use types. Fresh water had six land-use types in front of it. Although there were four land-use types in front of grassland, the rate of the four land-use types showed little difference. The land-use types behind fresh water, grassland, and construction land tended to be diverse with five land-use types. The land-use types in front of Cultivated Land and Forest Land tended to be simplified and were mainly unused land $(44.44 \%, 4 / 9)$ and cultivated land $(44.44 \%, 4 / 9)$, respectively. Meanwhile, the land-use types behind cultivated land and forest land also tended to be simplified with types and their rates. Cultivated land had only three land-use types behind it. Forest land had four land-use types behind it and the rate of the four types was only $11.11 \%(1 / 9)$, respectively. 


\subsection{Temporal and Spatial Pattern of CLUSPs from 1990 to 2010}

According to the percent of land use area (indicated by a length in this study) along the sea-land direction, we extract the land use pattern along the sea-land direction from 1990 to 2010 (Figure 8). Compared with the relative stability of land-use sequential location, the percent of land use areas in CLUSPs is variation from 1990 to 2010. The percent of tidal flat and unused land are continuously reducing from 1990 to 2010. Cultivated land and grassland are increasing in the period of 1990-2000 and reducing in the period of 2000-2010. Construction land and salt water are continuously increasing from 1990 to 2010. Fresh water and forest land are relatively stable from 1990 to 2010. Additionally, based on the continuous increasing or reducing percent of land use, we define the CLUSPs in 1990 as low-exploitation CLUSP (relative high percent of tidal flat and unused land, but the low percent of construction land and salt water). The CLUSPs in 2000 is defined as middle-exploitation CLUSP (relative middle percent of tidal flat and unused land, construction land, and salt water). The CLUSPs in 2010 is defined as high-exploitation CLUSP (relative high percent of construction land and salt water, but the low percent of tidal flat and unused land). Additionally, the CLUSPs with a similar sequential pattern of land use have similar land use percent along the sea-land direction, for example, the CLUSP 1 in 1990 and CLUSP in 2000.

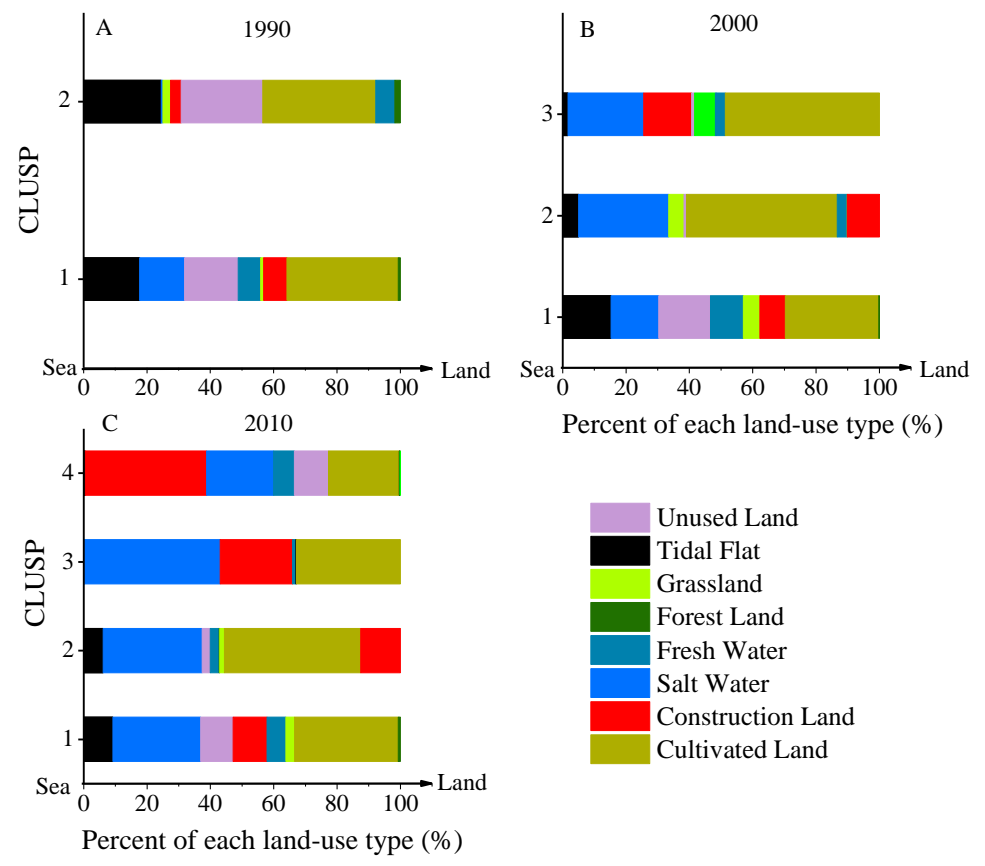

Figure 8. Land use pattern for 1990 (A), 2000 (B), and 2010 (C) along the sea-land direction.

As Figure 9 shows, the CLUSPs have temporal and spatial heterogeneity along the coast. In 1990, although the study area was mainly covered by Cluster 1 of the CLUSP, the coastal areas near to the Tangshan Port, Tianjin Port, and Huanghua Port still have some other CLUSP (the Cluster 2 of the CLUSP). In 2000, Cluster 1 of CLUSP was similar to Cluster 1 in 1990, is still the dominant CLUSP, and covers the majority of the study area. The other two CLUSPs tend to distribute around the port areas, particularly the Tangshan Port, Tianjin Port, and Huanghua Port where the new CLUSPs are taking places. In 2010, the temporal and spatial heterogeneity of CLUSPs became more obvious. There are four CLUSPs and all of them are scattering distribution along the coast. For example, Cluster 1 and Cluster 2 of the CLUSP are sounded by the other CLUSPs along the coast. However, Cluster 4 of the CLUSP still had an aggregated distribution and is mainly distributed around the port areas. From the above, we can know that the land use pattern along the sea-land direction shows a diversifying trend from 1990 to 2010, and the trend is more obvious in the port areas. 

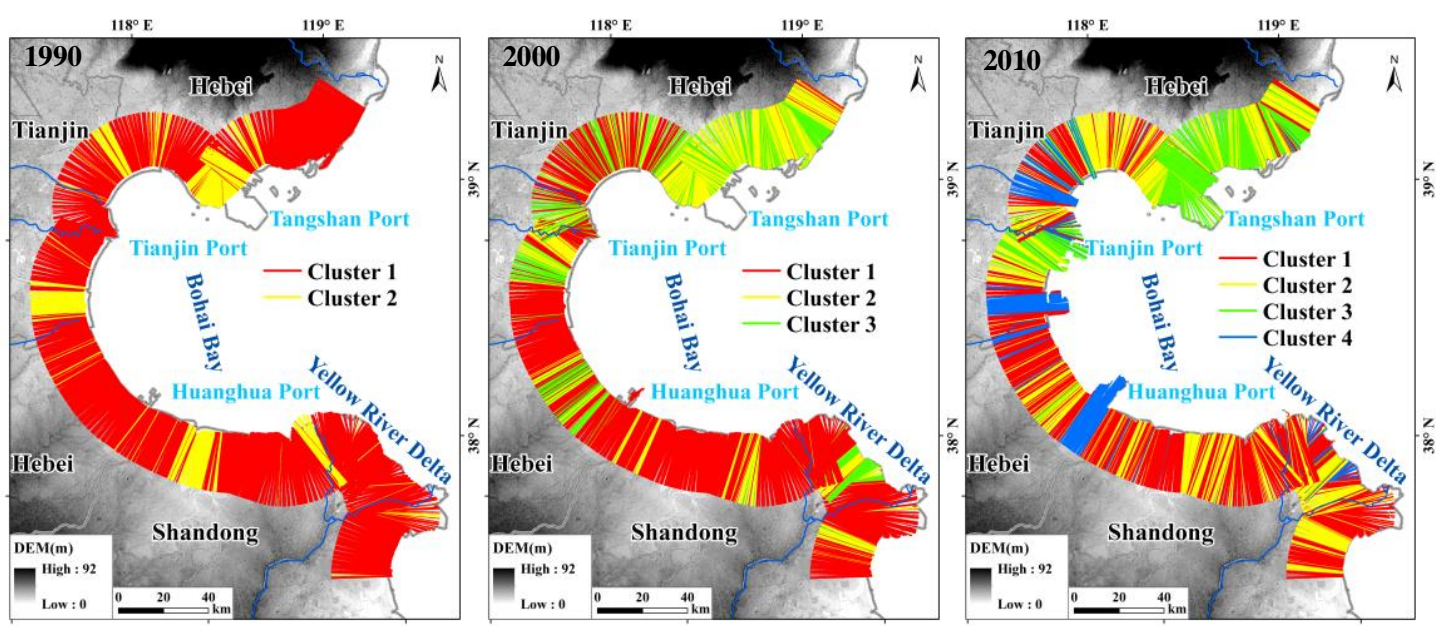

Figure 9. Spatial distribution of clusters of the CLUSPs from 1990 to 2010.

Additionally, the CLUSP in Bohai Bay and the YRD have some differences. The YRD is mainly covered by the relatively low-exploitation CLUSP with low percent of construction land. The sequential pattern of land use between these CLUSPs in the YRD has small changes. In all, the land use pattern along the sea-land direction in the YRD is relative stable. Compared with YRD, the relatively high-exploitation CLUSPs are mainly located in Bohai Bay. The difference of land-use sequential pattern along the sea-land direction tends to be more obvious with the more scattering distribution of CLUSPs in Bohai Bay from 1990 to 2010. Furthermore, the change areas of CLUSPs are mainly distributed in Bohai Bay.

\section{Discussion}

\subsection{The Relationships between CLUSP and Environmental Factors (Distance to Shoreline, Salinity, Water, and Landform)}

We extracted the average land-use distance to the shoreline from 1990 to 2010 and compared them with the sequential number (Figure 10). As Figure 10 shows, the land uses were sequentially distributed along the sea-land direction and each land-use type had relative stable locations indicated by both sequential number and average distance. Moreover, the trends of land-use locations along the sea-land direction for sequential number and average distance were almost the same. Therefore, the average sequential number could indicate the spatial distance of land use along the sea-land direction. The CLUSP also reveal the spatial distance pattern of land use along the sea-land direction, which may help to explore the seaward or landward trend of land use. The environmental factors (salinity, water, and landform) $[3-6,55]$ along the sea-land direction also had tight relationships with the CLUSP. On one hand, the salinity, water, and geomorphologic gradient determined the vegetation distribution in the sea-land direction $[6,7,55]$. Furthermore, the distribution of construction land, such as settlements and ports, were also largely limited by geomorphologic and hydrologic factors. Obviously, nobody wants to live in a low-lying area that is easily flooded and the locations of the harbors also require special hydrologic conditions like water depth. Therefore, the environmental factors were the basis of the CLUSPs in the sea-land direction. This was also the major reason why tidal flat, salt water, and cultivated land had a stable sequential location along the sea-land gradient. On the other hand, the CLUSP changes were also limited by the environmental factors along the sea-land gradient. The landward areas have good geomorphologic and soil conditions and offer good places for human living. Therefore, the major land-use changes happened around these areas, which promoted changes in the CLUSPs from 1990 to 2010. However, in seaward areas, human activities, such as sea reclamation for harbors and shrimp ponds, were largely affected by hydrologic conditions, like seawater. 


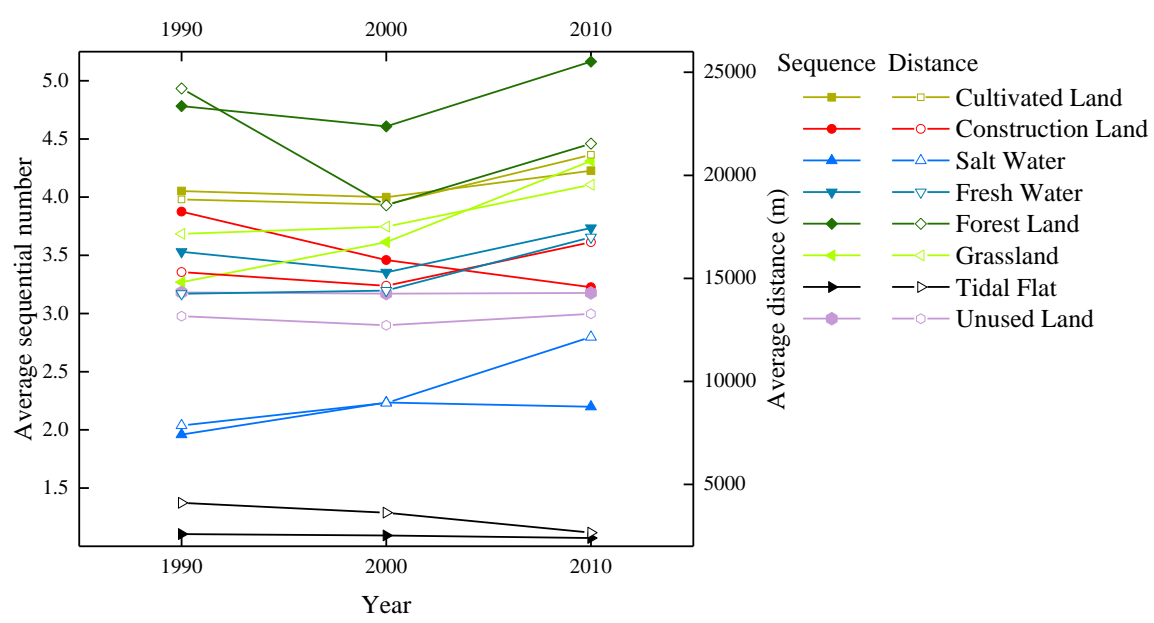

Figure 10. The comparison of the distance (average distance from land use to the shoreline) and a sequential number of land use along the sea-land direction from 1990 to 2010.

Marine factors, like tides, also affected the land-use change in the study area by erosion [56-58]. However, most of these changes mainly occurred around the places close to the shoreline where the change was relatively small, so tides had a limited impact on the coastal land use sequence pattern. Coastal morphology continually adapts to equilibrium as sea levels rise, leading to changes in the landscape [59], which might have profound impacts on coastal land use sequence patterns in the future.

\subsection{The Uncertainty of CLUSP along the Sea-Land Direction}

The uncertainty of CLUSP included two parts. The first part is the uncertainty of the spatial location of land use along the sea-land direction, like construction land. In the study area, Construction Land had the widest range of sequential number (2-8) along the sea-land direction. Although the area of salt water was continuous increasing, the spatial location of Salt Water was relatively stable. Both spatial location and area of construction land had obvious changes those may lead to the more diversity of CLUSPs. In fact, most of the new CLUSP were distributed around the port areas with high artificial level. Furthermore, many land-use conversions had indirect and direct relationships with the construction land (Tables 4 and 5). Therefore, the increased diversity of CLUSPs was mainly due to the spatial changes of construction land. The wide adaptivity of construction land made it widely distribute along the sea-land direction, which was also one important feature. Moreover, we also could know that largely land-use conversions (like salt water) may not change the land use sequential pattern along the sea-land direction and this may help to explore the stability of coastal land use pattern of along the sea-land direction. Theoretically, the average of the sequential number of land use may increase uncertainty. In Figure 10, the trend of sequential number and average distance for construction were not inconsistent with each other. However, the spatial location and overall land use pattern indicted by the average sequential number and distance were almost the same mentioned in Section 5.1. The second part of uncertainty was about the spatial heterogeneity of CLUSP along the coast. The works of literature $[8,22,60]$ had extracted the sequential trend of major land use and briefly analyzed the heterogeneity of them along the sea-land direction. However, the heterogeneity of CLUSP along the coast was rarely discussed and it had actually existed (Figure 9). Moreover, heterogeneity of CLUSP along the coast became salient in 2010 and a small coastal zone had contained multiple CLUSPs (Figure 9). The high spatial heterogeneity of CLUSP not only revealed the anisotropic distribution of land-use pattern along the sea-land direction but also indicated a spatial pattern of anthropic activities. For example, the CLUSP 4 in 2010, mainly distributed around the port areas, was one possible port-driven land use pattern along the sea-land direction. This typical land use pattern was helpful to understand the specific impacts from anthropic disturbance on the land use pattern along the sea-land direction and the spatial distribution of them along the coast. The better understanding 
of anthropic impacts on the coastal zone is one important part of coastal management and planning, which largely promoted the sustainable development of the coastal zone [61,62]. The method of subzone or subregion predefined by human subjectively would lose this high spatial heterogeneity in subzone or subregion. And the reasonable distance between coastal transect lines was defined accordingly to retain this high spatial heterogeneity in this study.

Table 4. Land use transformation matrix, 1990-2000 (in km).

\begin{tabular}{|c|c|c|c|c|c|c|c|c|c|c|}
\hline \multirow{2}{*}{1990} & \multicolumn{9}{|c|}{2000} & \multirow[b]{2}{*}{ Total } \\
\hline & SW & GL & FW & UL & CoL & TF & $\mathrm{CL}$ & Sea & FL & \\
\hline $\mathrm{CL}$ & 977.5 & 921.7 & 737.3 & 725.9 & 456.5 & 38.7 & 0 & & 11.8 & 3869.4 \\
\hline UL & 522.4 & 1416 & & 322.8 & 571.2 & 423.4 & 7.5 & 396.7 & 27.1 & 3687.1 \\
\hline $\mathrm{TF}$ & 1418.6 & 28.9 & 352.7 & 21.6 & & & 818.2 & 92.6 & & 2732.6 \\
\hline FW & 659.6 & 64.6 & 230.3 & 34.7 & & 194.3 & & 284.8 & & 1468.3 \\
\hline Sea & 204.5 & & 13.3 & 252.2 & & 16.8 & & & & 486.8 \\
\hline SW & & & 0.3 & 90.1 & 21.1 & 359.4 & & & & 470.9 \\
\hline GL & 3.7 & & 165.8 & 1.5 & 1.8 & & 0.2 & 35 & & 208 \\
\hline FL & & 194.2 & & & 0.7 & & & 8.7 & & 203.6 \\
\hline Total & 3786.3 & 2625.4 & 1499.7 & 1448.8 & 1051.3 & 1032.6 & 825.9 & 817.8 & 38.9 & $13,126.7$ \\
\hline
\end{tabular}

Table 5. Land use transformation matrix, 2000-2010 (in km).

\begin{tabular}{ccccccccccc}
\hline \multirow{2}{*}{$\mathbf{2 0 0 0}$} & \multicolumn{10}{c}{$\mathbf{2 0 1 0}$} \\
\cline { 2 - 10 } & SW & CoL & CL & UL & Sea & TF & FW & GL & FL & Total \\
\hline Sea & 359.2 & 2758 & 5.9 & 15 & & 513.6 & & & 5.2 & 3656.9 \\
TF & 2045.1 & 105.2 & 19.7 & 197.9 & 737.7 & & & 2.7 & & 3108.3 \\
CL & 1357 & 873.7 & & 115.9 & 1.2 & & 164.5 & 326.6 & 17.8 & 2856.7 \\
UL & 1213.3 & 116.6 & 898.4 & & 9.7 & 103.1 & 191.8 & 229 & 0.3 & 2762.2 \\
GL & 548.6 & 233.7 & 1037.1 & 425.9 & & 5.9 & 62 & & 127.1 & 2440.3 \\
FW & 1822.8 & 49.2 & 156.4 & 97.1 & 20.5 & 43.9 & & 4.6 & 0.4 & 2194.9 \\
SW & & 808.8 & 421.3 & 108.9 & 21.6 & 43.2 & & 0.1 & & 1403.9 \\
FL & & 2.2 & 43.7 & & & & & 2.6 & 48.5 \\
Total & 7346 & 4947.4 & 2582.5 & 960.7 & 790.7 & 709.7 & 418.3 & 565.6 & 150.8 & $18,471.7$ \\
\hline
\end{tabular}

\section{Conclusions}

In this study, we first developed a model, SCCLUP, to mine the major CLUSPs along the sea-land gradient. Then, we selected the coastal zone of Bohai Bay and the Yellow River Delta as the case study area to mine the major CLUSPs from 1990 to 2010. In the end, we mined two CLUSPs in 1990, three CLUSPs in 2000, and four CLUSPs in 2010. According to the CLUSPs for 1990, 2000, and 2010, we found the regular spatial location, sequential relationships of the land use along the sea-land direction and their heterogeneous spatial distribution along the coast. The temporal and spatial changes of the land use spatial location and sequential relationships were extracted. In addition, we discussed the tight correlation between CLUSP and environmental factors (distance to shoreline, salinity, water, and landform) and the major uncertainty of the spatial location of land use the sea-land direction and the heterogeneity of CLUSP along the coast. The conclusions of this study were as follows:

(1) The land use showed a sequential distribution along the sea-land direction. The land use closed to the shoreline (tidal flat, salt water, and unused land) and inland boundary (forest and cultivated land) had relative stable sequential location along the sea-land direction. However, the land uses located at the middle of the above had dynamic sequential locations that led to multiple CLUSPs along the coast.

(2) The CLUSPs had temporal and heterogeneity spatial along the coast and the heterogeneity became salient from 1990 to 2010. And due to the increasing percentage of construction land, the artificial 
level of CLUSP was continuously increasing and new CLUSPs tended to distribute around port areas. Different CLUSPs with similar land use sequential relationships tended to have similar land use structure along the sea-land direction.

(3) The land uses sequential location along the sea-land direction revealed the actual distance of land use to the shoreline. Additionally, the sequential pattern of land use along the sea-land direction had a tight correlation with environmental factors (salinity, water, and landform). The land use with large land-use conversions (like salt water with continuous increasing) might not lead to the changes of land use sequential pattern along the sea-land direction, and the construction land with large increasing and wide adaptivity was the major factor in the study area. Therefore, strong control should be provided for the excessive expansion of land use like construction land to limit the over changes in land use pattern along the sea-land direction. Additionally, the spatial heterogeneity of land use along the sea-land direction due to anthropic disturbance should be considered to better understanding of anthropic impacts on the coastal zone. A better understanding of anthropic impacts is one important part of coastal management and planning, which largely promoted the sustainable development of the coastal zone.

Author Contributions: Conceptualization, F.S.; Data curation, J.Z. and S.L.; Formal analysis, X.T.; Methodology, S.L.; Resources, Y.Z.; Supervision, X.T.; Writing-original draft, Z.D.

Funding: This study was supported by the National Natural Science Foundation of China $(41890854,41771361)$ and the National-level College Students' Innovative Entrepreneurial Training Plan Program (201810635035).

Acknowledgments: The land use dataset was provided by the Data Center for Resources and Environmental Sciences, Chinese Academy of Sciences (RESDC). We are very thankful to the anonymous reviewers and editors for their helpful and constructive comments.

Conflicts of Interest: The authors declare no conflict of interest.

\section{References}

1. Hadley, D. Land use and the coastal zone. Land Use Policy 2009, 26, S198-S203. [CrossRef]

2. Li, W.F.; Chen, Y.; Ma, R.F.; Yu, T.; Ren, L.Y.; Li, J.L. Land-use pattern in coastal zone from the perspective of development potentiality: A case study of the southern bank of Hangzhou bay. Geogr. Res. 2016, 35, 1061-1073.

3. Ray, G.C. Coastal-zone biodiversity patterns. Bioscience 1991, 41, 490-498. [CrossRef]

4. Luo, Y.M. Sustainability associated coastal eco-environmental problems and coastal science development in china. Bull. Chin. Acad. Sci. 2016, 31, 1133-1142.

5. Rath, J.S.; Hutton, P.H.; Chen, L.; Roy, S.B. A hybrid empirical-Bayesian artificial neural network model of salinity in the San Francisco Bay-Delta estuary. Environ. Model. Softw. 2017, 93, 193-208. [CrossRef]

6. Li, Y.; Zhang, H.; Li, Q.; Zhou, Q.; Chen, X.; Tu, C.; Luo, Y.; Christie, P.; Hu, X.; Li, L. Characteristics of residual organochlorine pesticides in soils under different land-use types on a coastal plain of the yellow river delta. Environ. Geochem. Health 2016, 38, 535-547. [CrossRef] [PubMed]

7. Feng, Y.; Sun, T.; Zhu, M.; Qi, M.; Yang, W.; Shao, D. Salt marsh vegetation distribution patterns along groundwater table and salinity gradients in yellow river estuary under the influence of land reclamation. Ecol. Indic. 2018, 92, 82-90. [CrossRef]

8. Hou, X.Y.; Xu, X.L. Spatial patterns of land use in coastal zones of china in the early 21st century. Geogr. Res. 2011, 30, 1370-1379.

9. Pielke, R.A. Land use and climate change. Science 2005, 310, 1625-1626. [CrossRef]

10. Ma, Z.; Melville, D.S.; Liu, J.; Chen, Y.; Yang, H.; Ren, W.; Zhang, Z.; Piersma, T.; Li, B. Rethinking China's new great wall. Science 2014, 346, 912-914. [CrossRef]

11. Zhu, G.; Xu, X.; Ma, Z.; Xu, L.; Porter, J.H. Spatial Dynamics and Zoning of Coastal Land-Use Change along Bohai Bay, China, during 1979-2008. J. Coast. Res. 2012, 28, 1186-1196.

12. Kirwan, M.L.; Megonigal, J.P. Tidal wetland stability in the face of human impacts and sea-level rise. Nature 2013, 504, 53-60. [CrossRef] [PubMed] 
13. Dasgupta, S.; Laplante, B.; Meisner, C.; Wheeler, D.; Yan, J. The Impact of Sea Level Rise on Developing Countries: A Comparative Analysis; The World Bank: Washington, DC, USA, 2007.

14. Cooper, N.J.; Cooper, T.; Burd, F. 25 years of salt marsh erosion in Essex: Implications for coastal defence and nature conservation. J. Coast. Conserv. 2001, 7, 31-40. [CrossRef]

15. Peng, B.; Lin, C.; Jin, D.; Rao, H.; Jiang, Y.; Liu, Y. Modeling the total allowable area for coastal reclamation: A case study of Xiamen, China. Ocean Coast. Manag. 2013, 76, 38-44. [CrossRef]

16. Hinkle, R.L.; Mitsch, W.J. Salt marsh vegetation recovery at salt hay farm wetland restoration sites on Delaware Bay. Ecol. Eng. 2005, 25, 240-251. [CrossRef]

17. Xin, P.; Gibbes, B.; Li, L.; Song, Z.; Lockington, D. Soil saturation index of salt marshes subjected to spring-neap tides: A new variable for describing marsh soil aeration condition. Hydrol. Process. 2010, 24, 2564-2577. [CrossRef]

18. Xin, P.; Jin, G.; Li, L. Modelling of tide induced pore water flow and solute transport in a salt marsh. Shui Kexue Jinzhan 2009, 20, 379-384.

19. Marani, M.; Da Lio, C.; D'Alpaos, A. Vegetation engineers marsh morphology through multiple competing stable states. Proc. Natl. Acad. Sci. USA 2013, 110, 3259-3263. [CrossRef] [PubMed]

20. Zhang, T.T.; Zeng, S.L.; Gao, Y.; Ouyang, Z.T.; Li, B.; Fang, C.M.; Zhao, B. Assessing impact of land uses on land salinization in the Yellow River Delta, China using an integrated and spatial statistical model. Land Use Policy 2011, 28, 857-866. [CrossRef]

21. Xu, Y.; Pu, L.; Zhang, R.; Zhu, M. Spatial-temporal dynamics of land use and land cover change in the coastal zone of jiangsu province. Resour. Environ. Yangtze Basin 2012, 21, 565-571.

22. Di, X.; Hou, X.; Wang, Y.; Wu, L. Spatial-temporal characteristics of land use intensity of coastal zone in china during 2000-2010. Chin. Geogr. Sci. 2015, 25, 51-61. [CrossRef]

23. Thieler, E.R.; Himmelstoss, E.A.; Zichichi, J.L.; Ergul, A. The Digital Shoreline Analysis System (DSAS) Version 4.0-An ArcGIS extension for calculating shoreline change. In Open-File Report; U.S. Geological Survey: Reston, VA, USA, 2009.

24. Thieler, E.R.; Martin, D.; Ergul, A. Digital Shoreline Analysis System (DSAS) version 2.0: An ArcView extension for calculating shoreline change. In Open-File Report; U.S. Geological Survey: Reston, VA, USA, 2003; pp. 1258-2331.

25. Sheik, M.; Chandrasekar. A shoreline change analysis along the coast between Kanyakumari and Tuticorin, India, using digital shoreline analysis system. Geo-Spat. Inf. Sci. 2011, 14, 282-293. [CrossRef]

26. Liu, Y.; Huang, H.; Qiu, Z.; Fan, J. Detecting coastline change from satellite images based on beach slope estimation in a tidal flat. Int. J. Appl. Earth Obs. Geoinf. 2013, 23, 165-176. [CrossRef]

27. Yang, R.; Liu, Y.; Long, H.; Qiao, L. Spatio-temporal characteristics of rural settlements and land use in the Bohai Rim of China. J. Geogr. Sci. 2015, 25, 559-572. [CrossRef]

28. Ren, Y.; Yansui, L.; Liying, G.; Yuheng, L. Spatial-temporal characteristics for rural hollowing and cultivated land use intensive degree: Taking the circum-bohai sea region in china as an example. Prog. Geogr. 2013, 32, 181-190.

29. Reynolds, A.P.; Richards, G.; Rayward-Smith, V.J. The application of k-medoids and pam to the clustering of rules. In Proceedings of the International Conference on Intelligent Data Engineering and Automated Learning, Exeter, UK, 25-27 August 2004; Springer: Berlin/Heidelberg, Germany, 2004; pp. 173-178.

30. Kaufman, L.; Rousseeuw, P.J. Partitioning around medoids (program pam). In Finding Groups in Data: An Introduction to Cluster Analysis; John Wiley \& Sons, Inc.: Hoboken, NJ, USA, 1990; pp. 68-125.

31. Reynolds, A.P.; Richards, G.; De La Iglesia, B.; Rayward-Smith, V.J.; Iglesia, B. Clustering Rules: A Comparison of Partitioning and Hierarchical Clustering Algorithms. J. Math. Model. Algorithms 2006, 5, 475-504. [CrossRef]

32. Xie, X.; Beni, G. A validity measure for fuzzy clustering. IEEE Trans. Pattern Anal. Mach. Intell. 1991, 13, 841-847. [CrossRef]

33. Vendramin, L.; Campello, R.J.G.; Hruschka, E.R. Relative clustering validity criteria: A comparative overview. Stat. Anal. Data Min. ASA Data Sci. J. 2010, 3, 209-235. [CrossRef]

34. Halkidi, M.; Vazirgiannis, M. Clustering validity assessment: Finding the optimal partitioning of a data set. In Proceedings of the 2001 IEEE International Conference on Data Mining, San Jose, CA, USA, 29 November-2 December 2001; pp. 187-194. 
35. Chouikhi, H.; Charrad, M.; Ghazzali, N. A comparison study of clustering validity indices. In Proceedings of the 2015 Global Summit on Computer \& Information Technology (GSCIT), Sousse, Tunisia, 11-13 June 2015; pp. 1-4.

36. Verdinelli, I.; Wasserman, L. Analysis of a mode clustering diagram. Electron. J. Stat. 2018, 12, 4288-4312. [CrossRef]

37. Qin, Y.; Yu, Z.L.; Wang, C.D.; Gu, Z.; Li, Y. A Novel clustering method based on hybrid K-nearest-neighbor graph. Pattern Recognit. 2018, 74, 1-14. [CrossRef]

38. Xu, X.; Ding, S.; Shi, Z. An improved density peaks clustering algorithm with fast finding cluster centers. Knowl. Based Syst. 2018, 158, 65-74. [CrossRef]

39. Rodriguez, A.; Laio, A. Clustering by fast search and find of density peaks. Science 2014, 344, 1492-1496. [CrossRef] [PubMed]

40. Hong, F.; Yang, J.; Hou, C.C.; Zhang, K.Z.; Yao, R.X. A fast density peak clustering algorithm optimized by uncertain number neighbors for breast MR image. J. Phys. Conf. Ser. 2019, 1229, 012024. [CrossRef]

41. Xu, D.; Tian, Y. A Comprehensive Survey of Clustering Algorithms. Ann. Data Sci. 2015, 2, $165-193$. [CrossRef]

42. Jia, S.; Tang, G.; Zhu, J.; Li, Q. A novel ranking-based clustering approach for hyperspectral band selection. IEEE Trans. Geosci. Remote Sens. 2015, 54, 88-102. [CrossRef]

43. Hou, J.; Gao, H.; Li, X. DSets-DBSCAN: A Parameter-Free Clustering Algorithm. IEEE Trans. Image Process. 2016, 25, 3182-3193. [CrossRef] [PubMed]

44. Arbelaitz, O.; Gurrutxaga, I.; Muguerza, J.; Pérez, J.M.; Perona, I.; Rivero, J.F.M. An extensive comparative study of cluster validity indices. Pattern Recognit. 2013, 46, 243-256. [CrossRef]

45. Milligan, G.W.; Cooper, M.C. An examination of procedures for determining the number of clusters in a data set. Psychometrika 1985, 50, 159-179. [CrossRef]

46. Davies, D.L.; Bouldin, D.W. A cluster separation measure. IEEE Trans. Pattern Anal. Mach. Intell. 1979, 224-227. [CrossRef]

47. Kim, M.; Ramakrishna, R. Some new indexes of cluster validity. Pattern Recognit. Lett. 2005, 26, $2353-2363$. [CrossRef]

48. Tseng, C.T.; Yang, C.B.; Ann, H.Y. Efficient algorithms for the longest common subsequence problem with sequential substring constraints. J. Complex. 2013, 29, 44-52. [CrossRef]

49. Frolova, D.; Stern, H.; Berman, S. Most Probable Longest Common Subsequence for Recognition of Gesture Character Input. IEEE Trans. Cybern. 2013, 43, 871-880. [CrossRef] [PubMed]

50. Ding, Z.; Liao, X.; Su, F.; Fu, D. Mining Coastal Land Use Sequential Pattern and Its Land Use Associations Based on Association Rule Mining. Remote Sens. 2017, 9, 116. [CrossRef]

51. Li, D.; Chen, S.; Guan, L.; Lloyd, H.; Liu, Y.; Lv, J.; Zhang, Z. Patterns of waterbird community composition across a natural and restored wetland landscape mosaic, Yellow River Delta, China. Estuar. Coast. Shelf Sci. 2011, 91, 325-332. [CrossRef]

52. Di, X.; Hou, X.; Wu, L. Land use classification system for china's coastal zone based on remote sensing. Resour. Sci. 2014, 36, 463-472.

53. Deng, X.; Huang, J.; Rozelle, S.; Uchida, E. Cultivated land conversion and potential agricultural productivity in China. Land Use Policy 2006, 23, 372-384. [CrossRef]

54. Liu, J.; Zhang, Z.; Xu, X.; Kuang, W.; Zhou, W.; Zhang, S.; Li, R.; Yan, C.; Yu, D.; Wu, S.; et al. Spatial patterns and driving forces of land use change in China during the early 21st century. J. Geogr. Sci. 2010, 20, 483-494. [CrossRef]

55. Batriu, E.; Ninot, J.M.; Pino, J. Filtering of plant functional traits is determined by environmental gradients and by past land use in a M editerranean coastal marsh. J. Veg. Sci. 2015, 26, 492-500. [CrossRef]

56. Gaoru, Z.; Xuegong, X. Annual processes of land reclamation from the sea along the northwest coast of bohai bay during 1974 to 2010. Sci. Geogr. Sin. 2012, 32, 1006-1012.

57. Thampanya, U.; Vermaat, J.; Sinsakul, S.; Panapitukkul, N. Coastal erosion and mangrove progradation of Southern Thailand. Estuar. Coast. Shelf Sci. 2006, 68, 75-85. [CrossRef]

58. Cao, W.; Wong, M.H. Current status of coastal zone issues and management in China: A review. Environ. Int. 2007, 33, 985-992. [CrossRef] [PubMed]

59. Passeri, D.L.; Hagen, S.C.; Medeiros, S.C.; Bilskie, M.V.; Alizad, K.; Wang, D. The dynamic effects of sea level rise on low-gradient coastal landscapes: A review. Earth's Future 2015, 3, 159-181. [CrossRef] 
60. Wang, J.; Liu, Y. Tourism-Led Land-Use Changes and their Environmental Effects in the Southern Coastal Region of Hainan Island, China. J. Coast. Res. 2013, 290, 1118-1125. [CrossRef]

61. Yu, L.; Hou, X.; Gao, M.; Shi, P. Assessment of coastal zone sustainable development: A case study of Yantai, China. Ecol. Indic. 2010, 10, 1218-1225. [CrossRef]

62. Sardá, R.; Avila, C.; Mora, J. A methodological approach to be used in integrated coastal zone management processes: The case of the Catalan Coast (Catalonia, Spain). Estuar. Coast. Shelf Sci. 2005, 62, 427-439. [CrossRef]

(c)

(C) 2019 by the authors. Licensee MDPI, Basel, Switzerland. This article is an open access article distributed under the terms and conditions of the Creative Commons Attribution (CC BY) license (http://creativecommons.org/licenses/by/4.0/). 